\title{
Simulation of the HiPowAR power generation system for steam-nitrogen expansion after ammonia oxidation in a high-pressure oxygen membrane reactor
}

\author{
Alberto Cammarata ${ }^{1, *}$, Paolo Colbertaldo ${ }^{1}$, and Stefano Campanari ${ }^{1}$ \\ ${ }^{1}$ Group of Energy Conversion Systems (GECOS), Department of Energy, Politecnico di Milano, Via \\ Lambruschini 4A, 20156, Milan, Italy
}

\begin{abstract}
The EU project HiPowAR studies a novel power generation system based on ammonia flameless oxidation with pure oxygen in a highpressure membrane reactor and expansion of the resulting hightemperature $\mathrm{H}_{2} \mathrm{O}-\mathrm{N}_{2}$ stream. The system combines the advantages of high temperature at expander inlet, typical of gas turbines, and small compression demand, typical of steam cycles. Water is injected into the reactor to control the very high adiabatic temperature, at the limited energy expenditure of liquid pumping. This work assesses the performance potential of the HiPowAR system under different design conditions, through simulations with a model developed in Aspen Plus ${ }^{\mathbb{R}}$. The system shows a high efficiency (up to 55\%) when operating at high temperature (e.g., $1350^{\circ} \mathrm{C}$ at expander inlet); hence, $\mathrm{O}_{2}$ membranes capable of working at very high temperature are required. The cycle features an optimal subatmospheric expansion pressure (in the range 0.1-0.2 bar), which requires the re-pressurization of the off-gas (steam-saturated nitrogen). The system also produces liquid water as a net output. A reduction of the expander inlet temperature to values acceptable by typical steam cycles $\left(600^{\circ} \mathrm{C}\right)$ significantly limits the efficiency, despite allowing to demonstrate the process using conventional steam expanders.
\end{abstract}

\section{Introduction}

Alternative fuels with low carbon content are widely investigated as a promising option for low- $\mathrm{CO}_{2}$ emission energy processes, studying innovative systems for their efficient exploitation. Ammonia $\left(\mathrm{NH}_{3}\right)$ is one of such fuels, able to act as a zero-carbon hydrogen carrier with advantages in terms of transportability and handling, thanks to the availability at liquid state at relatively low pressure. A significant amount of work has been developed in the scientific literature and in the industry to assess the feasibility of ammonia feeding in internal combustion engines, gas turbines, alkaline fuel cells (mostly adopting a cracking unit), and solid oxide fuel cells (directly or after cracking) [1-3].

\footnotetext{
*Corresponding author: alberto.cammarata@polimi.it
} 
The EU-funded project HiPowAR studies a novel power generation system based on ammonia oxidation in a high-pressure membrane reactor (MR) and subsequent expansion of the resulting high-temperature gas stream in a thermodynamic cycle [4]. The flameless oxygen-blown combustion is carried out at the external surface of thin tubular membranes made of Mixed Ionic Electronic Conductor (MIEC) materials, which selectively allow for the permeation of pure oxygen, driven by its partial pressure gradient between an ambientpressure air feed and the ammonia oxidation sites $[5,6]$. The system combines the advantages of high temperature at expander inlet, typical of gas turbine cycles with internal combustion, and small compression demand, typical of steam cycles.

This work aims at simulating and studying the performances of the HiPowAR system under different design conditions, with the purpose of assessing the potential in terms of efficiency and process scheme complexity. A model is developed in Aspen Plus ${ }^{\circledR}$, adopting a 0 -D description of the components. In order to control the very high adiabatic temperature of the oxidation reaction, in absence of dilution effects due to the presence of inert nitrogen from air, water is injected into the reactor as a moderator, at the limited energy expenditure of liquid pumping. Water is then recovered and partially recycled after condensation of the turboexpander outlet stream.

\section{Ammonia use as fuel}

Ammonia-based technologies for electricity generation have up to now featured little practical application and are therefore relatively immature in general. Currently, the only commercially available option is the alkaline fuel cell, coupled with $\mathrm{NH}_{3}$ cracking [7]. However, this type of technological option is expected to significantly improve and possibly diffuse more widely in the future.

The academic and industrial research on $\mathrm{NH}_{3}$-based technologies such as gas turbines (GTs), internal combustion engines (ICEs), and fuel cells (FCs) is very active. As an example, the Japanese government included all these technologies in a Strategic Innovation Promotion Program (SIP) named 'Energy Carriers', which started in 2014 [8]. This research has produced encouraging and unprecedent results for several $\mathrm{NH}_{3}$-based technologies in the last few years. In Europe, a large consortium belonging to the Campfire project has been developing advanced technologies for ammonia production and utilization [9]. The project, funded by the German Federal Ministry for Education and Outreach, is particularly focused on the decarbonisation of maritime transportation. Nevertheless, the studied technologies go far beyond the specific maritime application.

\subsection{Ammonia in internal combustion engines}

Ammonia utilization in internal combustion engines is attracting a lot of attention especially for the decarbonization of the maritime sector. For instance, MAN Energy Solutions and Wärtsilä recently started projects for the development of $\mathrm{NH}_{3}$-fed ICEs.

The early work on ammonia combustion engines mainly started for military applications [10-14]. It was concluded that, due to the poor combustion characteristics of ammonia, some of the following combustion promotion strategies have to be implemented:

- relatively high compression ratio (CR), e.g., Gray et al. [12] found that a CR as high as 35:1 was necessary to use neat $\mathrm{NH}_{3}$ as a fuel in a compression ignition engine;

- $\quad$ use of a spark ignition, with relatively large spark energy [14];

- blending with a more reactive fuel as $\mathrm{H}_{2}$, possibly derived by $\mathrm{NH}_{3}$ cracking; it was found that $\mathrm{H}_{2}$ concentration in the fuel of $3-5 \%$ by weight could be sufficient [13], corresponding to $15-25 \%$ ammonia dissociation. 
The idea of adopting a spark ignition to avoid very large compression ratios is supported by the high octane number of ammonia $(\mathrm{RON} \approx 110$ ), which makes it hard to auto-ignite. On the other hand, the high octane number is an advantage in spark ignition engines, as it provides knocking resistance allowing for larger compression ratios and efficiencies. As an example, Mørch et al. [1] showed that a $\mathrm{NH}_{3}-\mathrm{H}_{2}$ mixture of $90-10 \%$ vol could reach $37 \%$ efficiency with a $\mathrm{CR}=11.64$. Alternatively, research has been carried on by introducing the concepts of pilot injection and dual fuel operation, either with diesel (for compression ignition) or gasoline (for spark ignition). Such solutions would still rely on hydrocarbons, differently from the scope of HiPowAR plant that aims at being a full decarbonization option.

The ICE concept that could directly compare to the HiPowAR plant is a spark ignition engine operating on either pure $\mathrm{NH}_{3}$ or a mixture of $\mathrm{NH}_{3}-\mathrm{H}_{2}$ attainable via $\mathrm{NH}_{3}$ cracking. Indeed, operation with neat $\mathrm{NH}_{3}$ has been hardly considered, while cracking a very low quantity of $\mathrm{NH}_{3}$ seems to be sufficient to significantly improve the combustion and cyclic stability of spark ignition engines even at part load. Mørch et al. [1] found that it was possible to run the engine on pure $\mathrm{NH}_{3}$, but with a strong tendency to cut out. With addition of $5 \%$ vol of $\mathrm{H}_{2}$ in the fuel, instead, the engine run smoothly. This corresponds to cracking only $4 \%$ of the $\mathrm{NH}_{3}$ fuel. Also Lhuillier et al. stabilized pure $\mathrm{NH}_{3}$ combustion, but a small amount of $\mathrm{H}_{2}$ was necessary in most cases to ensure ignitability and stability [15].

However, the amount of $\mathrm{H}_{2}$ in the fuel mixture should be minimized to reduce both the cracker size and the energy required for cracking. Other reasons are the higher $\mathrm{NO}_{\mathrm{x}}$ production $[16,17]$ and the lower efficiency and power output at high $\mathrm{H}_{2}$ content $[1,15$, 16]. Nevertheless, it is well understood that a higher amount of $\mathrm{H}_{2}$ would increase the combustion efficiency and the engine cyclic stability. Frigo and Gentili [18] found that cracking $6-10 \%$ of the input ammonia was sufficient to keep the power output stable. Mørch et al. [1] found that a $90-10 \% \%_{\text {vol }} \mathrm{NH}_{3}-\mathrm{H}_{2}$ mixture was optimal regarding efficiency and power output, and this corresponds to $7 \%$ ammonia dissociation. Lhuillier et al. [15] found that the best performance is achieved with $\mathrm{H}_{2}$ content below $20 \%$ vol, providing efficiency values close to $39 \%$.

According to the literature reviewed, adding a cracking reactor and converting $5-15 \%$ of the input $\mathrm{NH}_{3}$, generating a fuel mixture with $7-20 \%$ vol of $\mathrm{H}_{2}$, would provide sufficient cyclic stability and combustion efficiency while limiting the efficiency penalization, the $\mathrm{NO}_{\mathrm{x}}$ emissions, and the cracking apparatus size. Apart from that, modern spark ignition ICEs can be adapted to operate with $\mathrm{NH}_{3}$ without significant layout changes. The major modifications in the equipment are the $\mathrm{NH}_{3}$ fuel tank and supply line, which would result in larger space requirements due to relatively low $\mathrm{NH}_{3}$ volumetric energy density [19].

\subsection{Ammonia in gas turbines}

Ammonia utilization in gas turbines is a promising application for the widespread use of this chemical as an energy vector for low-carbon power generation. Despite the poor combustion properties of $\mathrm{NH}_{3}$, its utilization as a fuel in gas turbine combustors has been proved experimentally in conditions comparable to real world applications, achieving hydrocarbon-like efficiencies. For instance, this was demonstrated by Kurata and coworkers by implementing a $50-\mathrm{kW}_{\mathrm{el}}$ test rig within the SIP program [3].

Several methods have been proved effective when it comes to enhance ammonia combustion stability, such as cracking part of the $\mathrm{NH}_{3}$ to produce $\mathrm{H}_{2}$, generating swirling flows inside the combustor, increasing the combustor inlet temperature, and working under a suitable Equivalence Ratio (ER) to avoid lean or rich blowouts, as well as flashback risks $[3,20]$. According to the literature reviewed, it is predicted that cracking between $15 \%$ and $35 \%$ of the $\mathrm{NH}_{3}$ would result in a good trade-off between combustion properties, flame 
stability, and $\mathrm{NO}_{\mathrm{x}}$ emissions: with a large $\mathrm{H}_{2}$ fraction the resulting mixture shows similar combustion properties to $\mathrm{CH}_{4}$, whereas a low $\mathrm{H}_{2}$ fraction favours low $\mathrm{NO}_{\mathrm{x}}$ and easier cracking.

By the point of view of emissions, it is possible to achieve a very low $\mathrm{NH}_{3}$ slip and $\mathrm{NO}_{x}$ emissions by using SCR technology. Nevertheless, the required equipment is large and potentially expensive [21], hence strategies for $\mathrm{NO}_{\mathrm{x}}$ formation reduction are under development. An important driver for $\mathrm{NO}_{x}$ production is the local ER. The mixture must be either slightly rich $(\mathrm{ER} \approx 1.05-1.3)$ with a second combustion stage to complete the oxidation, or very lean $(E R<0.7)$. In the latter case, a small percentage of $\mathrm{H}_{2}$ in the fuel mixture would avoid lean blowout. Other possible methods to limit $\mathrm{NO}_{\mathrm{x}}$ production are the optimization of premixed combustion, fuel and air staged injection strategies, combustor pressure increase, water vapour injection, and optimization of $\mathrm{H}_{2}$ fraction in the fuel [22-25].

Efficient chemical-kinetics models capable of predicting species concentrations with good accuracy for a wide range of operating conditions are fundamental for the development of $\mathrm{NH}_{3}$-based gas turbines. The development of such models is the basis for running 3D CFD simulations of the combustion process, like it is currently done for the combustion of methane and other hydrocarbons. Once this is achieved, the combustor design, including the amount of $\mathrm{H}_{2}$ blending and the $\mathrm{NO}_{\mathrm{x}}$ reduction strategy, will be easily optimized. Despite in recent years some work has been done towards the development of chemical-kinetics models [26-29], the available ones are not applicable for a wide range of operating conditions, and there is a general lack of detailed chemical mechanism studies.

\subsection{Ammonia in fuel cells}

Ammonia is also studied for use in fuel cells, mostly Alkaline or Solid Oxide fuel cells. $\mathrm{NH}_{3}$-based alkaline fuel cell (AFC) systems have been studied mainly for off-grid applications, such as powering base transceiver stations for telecommunication applications $[7,30]$. The AFC system is currently claimed to be the only commercially available option for $\mathrm{NH}_{3}$-based power generation [7]. This technology relies on complete $\mathrm{NH}_{3}$ cracking before feeding a nitrogen and hydrogen mixture to the cell:

$$
\mathrm{NH}_{3} \rightarrow 0.5 \mathrm{~N}_{2}+1.5 \mathrm{H}_{2} \quad \Delta H^{\circ}=46.0 \mathrm{~kJ} / \mathrm{mol}_{\mathrm{NH}}
$$

Despite the relatively high level of maturity of the $\mathrm{NH}_{3}$-based AFC system, it is difficult to evaluate its performance due to the lack of data both on the cracker and on the cells, with limited literature work regarding such system. According to data disclosed by Gencell [31], the system could currently achieve $40 \%$ electric efficiency. This is also supported by one literature work [32] and by data from the Alkammonia project [30]. Nevertheless, current estimates foresee that once the system components and their arrangement are optimized, the electric efficiency could achieve $50 \%$.

On the opposite side, solid oxide fuel cells (SOFCs) could be directly fed with $\mathrm{NH}_{3}$, an option which is gaining high interest, due to the encouraging results achieved. The technology is still confined at a laboratory scale, with the highest power output reported being $1 \mathrm{~kW}$ [2]. Most published papers are experimental works, aimed at assessing the influence of operating parameters, performance durability over time, performance under stress conditions and materials degradation due to ammonia fuelling [2, 33-35]. Some works addressing cell-level and system-level modelling have also been published [36, 37].

Despite cracking part of the $\mathrm{NH}_{3}$ upstream the SOFC stack may alleviate degradation issues, the preferred configuration implements direct $\mathrm{NH}_{3}$ utilization. Nevertheless, fast $\mathrm{NH}_{3}$ decomposition into $\mathrm{H}_{2}$ and $\mathrm{N}_{2}$ within the cell is crucial for successful power generation, since the electro-oxidation process involves only $\mathrm{H}_{2}$. The main parameter 
controlling $\mathrm{NH}_{3}$ decomposition is the operating temperature. A higher temperature boosts the kinetics of chemical and electrochemical reactions and pushes the thermodynamic limit of $\mathrm{NH}_{3}$ conversion towards higher values due to its endothermic nature. Nevertheless, it is widely recognized that an excessively high temperature leads to unacceptable materials degradation; hence, it is important to find alternative routes to enhance $\mathrm{NH}_{3}$ conversion. The Ni-based materials conventionally used in SOFC fuel electrodes seem to be a valid catalyst for $\mathrm{NH}_{3}$ decomposition [38]. A long-term solution is to find catalysts tailored for $\mathrm{NH}_{3}$ decomposition, which is driving some research work [39].

Commercial SOFCs fed with $\mathrm{NH}_{3}$ perform surprisingly well (provided that $\mathrm{NH}_{3}$ is successfully converted into $\mathrm{H}_{2}$ ), but slightly worse if compared to the direct feeding of an equivalent amount of $\mathrm{H}_{2}$. This is generally attributed to the lower temperatures achieved inside the stack, due to the cooling effect of internal decomposition. However, the worse cell performance may be counterbalanced at the system level by a lower consumption of the air compressor due to a lower cell cooling requirement [40], while the possibility to avoid the cracker considerably simplifies the plant layout.

The $\mathrm{NH}_{3}$-based SOFC system is a relevant comparison for the HiPowAR plant concept, since they feature some similarities related to the presence of a $\mathrm{O}_{2}$ membrane and the high efficiency target. The electric efficiency of a $\mathrm{NH}_{3}$-based SOFC system was computed in [40], showing a relatively large efficiency range (35-65\%). However, considering only the cases with utilization factor equal to $0.7-0.8$ and cell voltage equal to $0.7-0.85 \mathrm{~V}$, the estimated electric efficiency ranges between $45-60 \%$.

\section{The HiPowAR system}

The power generation system proposed in the HiPowAR project is based on a flameless combustion carried out at the surface of a MIEC membrane, which is capable of conducting both oxygen ions $\left(\mathrm{O}^{2-}\right)$ and electrons at temperature above approximately $800^{\circ} \mathrm{C}$. Therefore, such MIEC materials are permeable to molecular oxygen. Within the HiPowAR approach, the MR is equipped with tubular, one-side closed membrane tubes with small diameter and wall thickness (capillaries). The membranes are flushed with air, with little energy expenditure to drive a fan. Oxygen enters spontaneously the combustion zone against the total pressure difference between the capillary and the reactor thanks to the steep gradient of $\mathrm{O}_{2}$ partial pressure, which is always very low within the reactor provided that oxygen is readily consumed by the fuel through the ammonia oxidation reaction:

$$
\mathrm{NH}_{3}+0.75 \mathrm{O}_{2} \rightarrow 0.5 \mathrm{~N}_{2}+1.5 \mathrm{H}_{2} \mathrm{O}
$$

The combustion process generates a stream of hot and pressurized exhaust gases, at the expense of feeding ammonia under pressure. However, ammonia can be pumped as a liquid before injection, without requiring a high compression duty. The system can be connected to a gas expander, similarly to the case of a gas turbine, but, in contrast to conventional gas turbine cycles, the oxidant stream does not require compression to the maximum system pressure, with positive impact on the cycle efficiency. However, since the adiabatic combustion temperature of $\mathrm{NH}_{3}$ in pure oxygen is unacceptably high (e.g., $3511^{\circ} \mathrm{C}$ with reactants at $25^{\circ} \mathrm{C}$ ), a temperature moderator shall be also injected in the membrane reactor; the choice is to inject water as a moderating agent, so that the final outlet stream from the MR is a mixture of $\mathrm{H}_{2} \mathrm{O}$ and $\mathrm{N}_{2}$, which is expanded in a turbine to generate work.

Another option for the implementation of the HiPowAR system, which is not investigated in this work, leverages the so-called 'self-pressurizing' combustion [41]. The flameless combustion would be carried out in a closed MR, in which the combustion products self-pressurize during the combustion process due to temperature and moles 
increase. The latter is enhanced by the presence of the $\mathrm{O}_{2}$ membrane, since $\mathrm{O}_{2}$ is not initially present in the gas phase. If a moderating agent is not used, it is possible to double the reactor pressure just by considering the number of moles variation in reaction (3). In this implementation, at least two reactors would be required to guarantee continuous cyclic operation.

\subsection{Scheme A: constrained pressure ratio}

Figure 1 shows the first configuration studied for the final implementation of the HiPowAR system. Liquid ammonia (stream 1) enters the system at ambient temperature. The pressure depends upon ambient temperature since liquid-vapour equilibrium is established inside the tank that is typically used for fuel storage. As an example, the saturation pressure of ammonia at $25^{\circ} \mathrm{C}$ is 9.9 bar. After pressurization to 50 bar through a pump, $\mathrm{NH}_{3}$ is vaporized in a regenerative heat exchanger and fed to the membrane reactor. The outlet flow of the reactor (stream 4) is expanded to atmospheric pressure in a turbine to generate useful work.

After preheating the liquid water to be used as a moderator, the latent heat available in the turbine outlet flow (stream 6) is used to completely vaporize the inlet ammonia. This is always possible when the maximum and minimum pressure levels of the system are 50 bar (or lower) and 1 bar, respectively, since $\mathrm{NH}_{3}$ would evaporate at about $89^{\circ} \mathrm{C}$ and the waternitrogen mixture would start condensing at about $100^{\circ} \mathrm{C}$ (due to the very large fraction of water). Stream 6 is a mixture of $\mathrm{H}_{2} \mathrm{O}$ and $\mathrm{N}_{2}$, hence the condensation temperature is not strictly constant. Nevertheless, a large fraction of $\mathrm{H}_{2} \mathrm{O}$ is expected, and condensation is found to be almost isothermal within the evaporator, where a minor fraction of heat is exchanged, and with a larger glide (e.g., $60^{\circ} \mathrm{C}$ ) on the condenser. Note that if the maximum system pressure is increased up to the point where $\mathrm{NH}_{3}$ evaporates above $100^{\circ} \mathrm{C}$, the amount of heat recovered after the expander would suddenly drop. Therefore, only a very large increase of the MR pressure, which determines the $\mathrm{NH}_{3}$ evaporation temperature, is expected to be beneficial for the system efficiency.

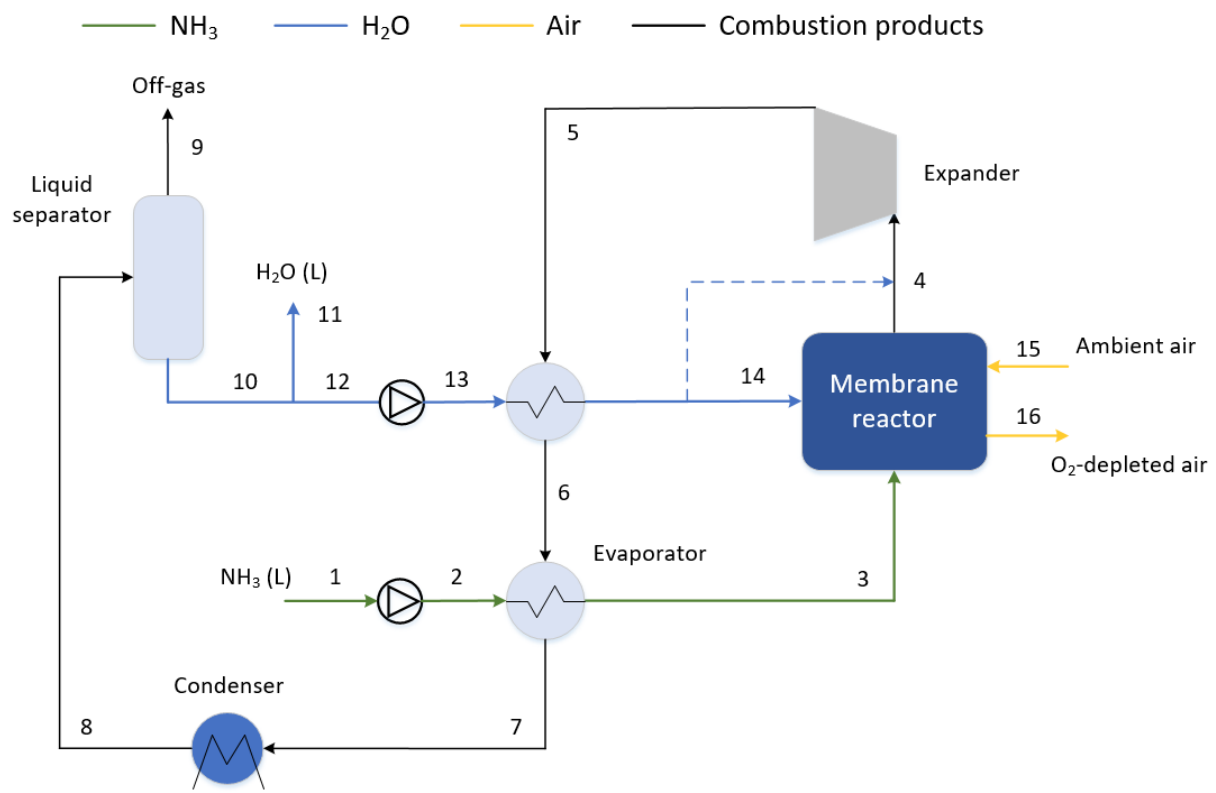

Fig. 1. Scheme A, configuration with atmospheric turbine discharge pressure. 
The condenser is required to recover the liquid water needed for cooling the MR. The temperature at condenser outlet is set to $40^{\circ} \mathrm{C}$ to minimize the water vapour mass flow rate in stream 9. Therefore, a significant amount of liquid water is allowed to leave the system as a useful output (stream 11). The following equation expresses the water mass flow rate leaving the system in stream $9\left(\mathrm{MM}_{\mathrm{H} 2 \mathrm{O}}\right.$ is the molar mass of water):

$$
m_{\mathrm{H} 2 \mathrm{O}, 9}=0.5 \cdot M M_{\mathrm{H} 2 \mathrm{O}} \cdot n_{1} /\left(p_{\text {cond }} / p_{\text {sat }, \mathrm{H} 2 \mathrm{O}}\left(T_{\text {cond }}\right)-1\right)
$$

where $n_{1}$ is the molar flow rate of the input ammonia fuel (stream 1). This expression has been derived by assuming that all nitrogen atoms embedded in the input ammonia leave the system in stream 9 (i.e, $\mathrm{N}_{2}$ is a non-condensable species). Therefore, the nitrogen atoms balance relates the input ammonia molar flow rate to the molar flow rate of stream 9. The Raoult's law is assumed valid for the liquid-vapour equilibrium of $\mathrm{H}_{2} \mathrm{O}$, so that:

$$
x_{H 2 O, 9}=p_{H 2 O, 9} / p_{\text {cond }}=p_{\text {sat }, H 2 O}\left(T_{\text {cond }}\right) / p_{\text {cond }}
$$

Therefore, it is demonstrated that a lower $\mathrm{T}_{\text {cond }}$ decreases the water mass flow rate in stream 9. The molar flow rate of hydrogen atoms embedded in the input ammonia is fixed; hence, if a lower molar flow rate of water exits the system in stream 9, the molar flow rate of stream 11 must increase. At first sight, it could be assumed that cooling to $40^{\circ} \mathrm{C}$ would decrease the system efficiency since stream 12 is at a lower temperature. Nevertheless, all streams below $100^{\circ} \mathrm{C}$ (if the minimum system pressure is atmospheric) could be heated with the latent heat of the turbine discharge stream, as done for $\mathrm{NH}_{3}$ evaporation. The liquid water mass flow rate required for MR cooling (stream 12) is pressurized, preheated, and finally injected into the reactor.

The expansion ratio across the turbine in the configuration shown in Fig. 1 is fixed to about 50, since the expansion pressure is atmospheric and the pressure within the MR is 50 bar. The operation of the membranes used in the HiPowAR project at 50 bar is yet to be proven, hence this pressure level is a target to be demonstrated within the project. A possible option for efficiency improvement is to investigate pressure levels different from the 1 bar-50 bar values, which still allow the heat integration between $\mathrm{H}_{2} \mathrm{O}$ condensation and $\mathrm{NH}_{3}$ evaporation. The aim is to find pressure levels that allow an increased expansion ratio across the turbine. Table 1 reports some pressure level combinations that have been calculated in this work, in all cases keeping a pinch-point temperature difference between the saturation temperature of $\mathrm{H}_{2} \mathrm{O}$ and that of $\mathrm{NH}_{3}$ approximately equal to $10^{\circ} \mathrm{C}$.

Table 1. Set of pressure level combinations that allow to exploit the heat integration between turbine outlet stream condensation and $\mathrm{NH}_{3}$ vaporization $\left(\Delta \mathrm{T}_{\text {pinch-point }}=10^{\circ} \mathrm{C}\right)$.

\begin{tabular}{llllllll}
\hline Variable & units & & & & & & \\
\hline $\mathrm{p}_{\text {cond }, \mathrm{H}_{2} \mathrm{O}=\mathrm{p}_{\text {out }, \text { turb }}}$ & {$[\mathrm{bar}]$} & 0.15 & 0.2 & 0.25 & 0.5 & 0.75 & 1.0 \\
$\mathrm{p}_{\text {eva }, \mathrm{NH}_{3}=\mathrm{p}_{M R}}$ & {$[\mathrm{bar}]$} & 17.5 & 20.5 & 23.0 & 33.8 & 42.3 & 50.0 \\
\hline
\end{tabular}

Note that the investigated pressure levels are lower than the original 1 bar-50 bar, due to the increasing trend of the expansion ratio available for the turbine. Therefore, exploring pressure levels larger than the combination 1 bar-50 bar is considered not interesting, as it would lead to a decrease in the system efficiency while the pressure within the MR would increase, with further complications regarding the sealing technology and the membranes mechanical resistance. Since the minimum system pressure becomes sub-atmospheric, a compressor is required to allow venting the off-gas into the atmosphere. At very low pressure, the compressed off-gas reaches a significantly large temperature. Therefore, it can be used to preheat the $\mathrm{NH}_{3}$ entering the MR when possible. These modifications lead to a varied configuration of scheme A, as presented in Fig. 2. 


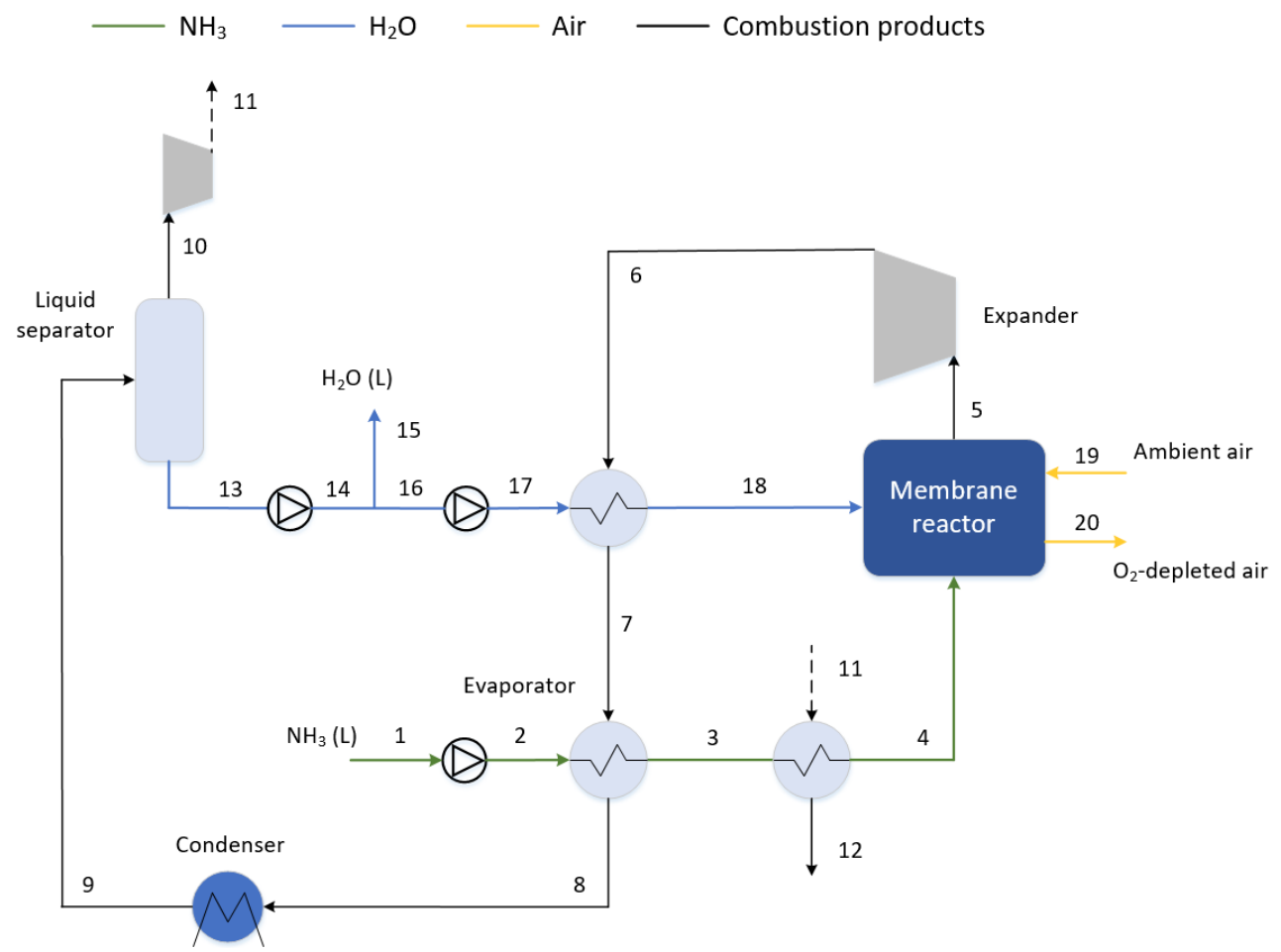

Fig. 2. Scheme A, configuration with sub-atmospheric expansion.

Also in this case, the temperature at condenser outlet is set to the minimum possible value of $40^{\circ} \mathrm{C}$. Apart from increasing the water production (stream 15), this decreases the $\mathrm{H}_{2} \mathrm{O}$ mass flow rate to be compressed in the off-gas as proven by equation (4). Considering that it is easier to compress a cold gas, a lower condensing temperature would have a double effect on compressor consumption reduction, decreasing both the specific work required and the mass flow rate to be compressed.

Since the off-gas stream (stream 10) must be compressed to ambient pressure, an optimum for the turbine discharge pressure is expected. A lower pressure increases the pressure ratio of the turbine, but also that of the compressor. Moreover, a lower turbine outlet pressure would increase the mass flow rate of water vapour at compressor inlet, further increasing its consumption. This is also demonstrated by equation (4).

The sub-atmospheric implementation of scheme A allows to operate the MR at a relatively low pressure, which would reduce the mechanical stress on the membranes and the issues related to the sealing technology. Note that oxygen membranes have been tested so far only up to about 20 bar [42], hence this scheme could provide an efficient and 'low risk' implementation of the HiPowAR system. The lower reactor pressure would also increase the driving force for oxygen permeation, which is expected to reduce the required membrane area, eventually reducing the investment costs. Finally, the heat exchangers would work under a lower differential pressure, which would allow an easier design.

\subsection{Scheme B: independent pressure levels}

In scheme $\mathrm{B}$, which is shown in Fig. 3, the synergy between $\mathrm{NH}_{3}$ evaporation and $\mathrm{H}_{2} \mathrm{O}$ condensation is not leveraged, hence the minimum and maximum system pressure are not related. 


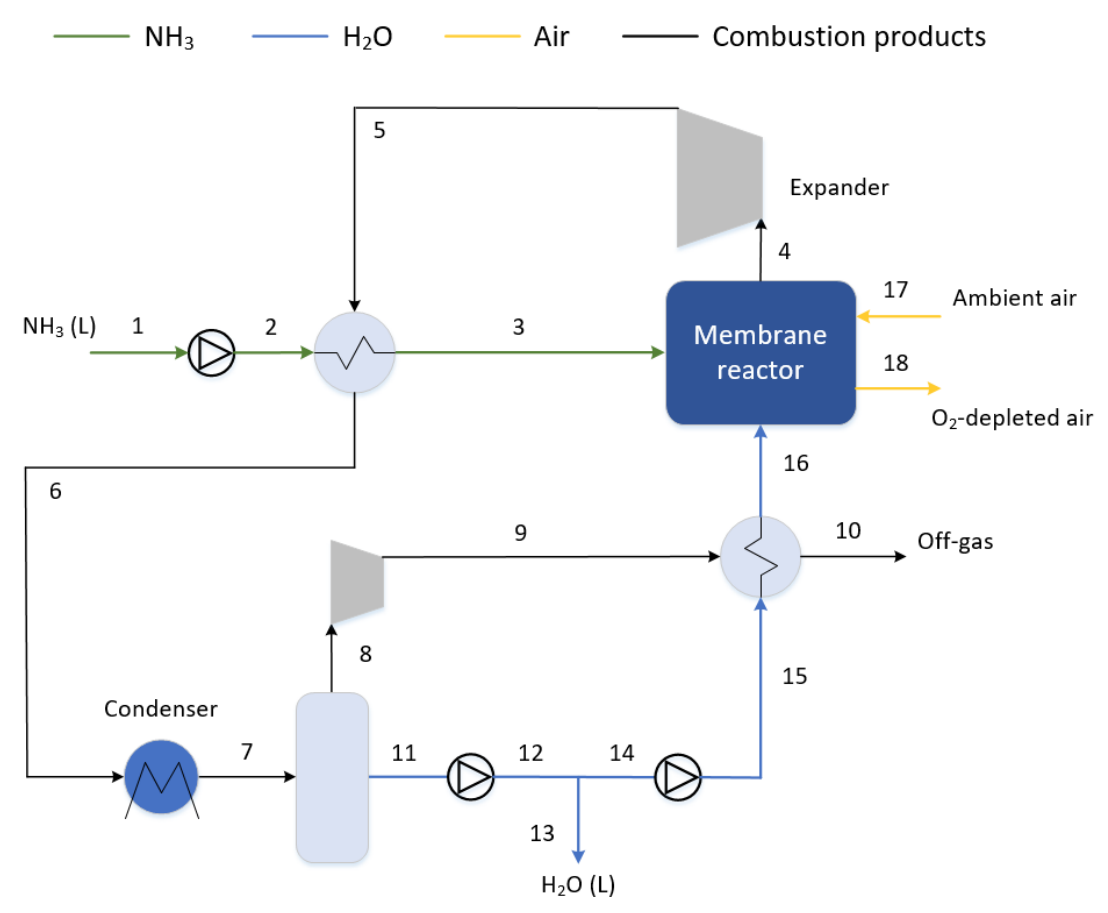

Fig. 3. Scheme B, system configuration with unconstrained pressure ratio.

The sensible heat in the turbine discharge flow is used to vaporize the inlet ammonia. This is because the presence of liquid droplets should be avoided inside the reactor and it is preferred to act with regeneration on the ammonia stream, since a system for water evaporation inside the MR is required in any case. The main advantage compared to scheme $\mathrm{A}$ is the possibility to work with a very large expansion ratio in the turbine, given by the high pressure within the MR (e.g., 50-100 bar or larger) and the implementation of sub-atmospheric expansion. If the expansion pressure is sub-atmospheric, a compressor is required to allow venting the off-gas into the atmosphere. At very low expansion pressure, the heat available in stream 9 is also recovered for regeneration, as shown in Fig. 3. In case the minimum system pressure is sub-atmospheric, it is possible to find an optimal minimum pressure value that provides the maximum efficiency.

\section{System modelling}

Table 2 summarizes the general assumptions used for all simulations. The oxygen utilization is the ratio between the oxygen mass flow rate which permeates the membranes (always stoichiometric to the input fuel) and the one entering the reactor. All simulations are run considering a net electric output of $100 \mathrm{MW}$.

Apart from the common general assumptions indicated in Table 2, some major parameters should be set to run the simulations. In particular, the Turbine Inlet Temperature (TIT) is expected to significantly affect the results, especially the system efficiency. The selection of a reasonable TIT should consider both the membrane and the turbine blade resistance. Therefore, four different scenarios are selected according to different levels of technological development, for simplicity assuming in all cases to avoid the adoption of turbine cooling: 
Table 2. Simulation assumptions.

\begin{tabular}{ll}
\hline$\underline{\text { Machines }}$ & $\begin{array}{l}\text { Ambient conditions } \\
\eta_{\text {is,turb }}=0.9\end{array}$ \\
$\eta_{\text {is, comp }}=0.85$ & Temperature $=25^{\circ} \mathrm{C}$ \\
$\eta_{\text {ad, pumps }}=0.75$ & Pressure $=1.01325$ bar \\
$\eta_{\text {mech,turb } / \text { comp }}=0.98$ & $\underline{\text { Miscellaneous }}$ \\
& $\mathrm{NH}$ tank pressure $=\mathrm{P}_{\text {sat }}\left(\mathrm{T}_{\text {amb }}\right)$ \\
Heat exchangers & $90 \%$ oxygen utilization \\
$15^{\circ} \mathrm{C}$ minimum gas-gas pinch point & Temperature of $\mathrm{O}_{2}$-depleted air is $100^{\circ} \mathrm{C}$ \\
$10^{\circ} \mathrm{C}$ minimum gas-liquid pinch point & MR heat loss is $2 \%$ of inlet fuel LHV \\
$40^{\circ} \mathrm{C}$ at condenser outlet & Pressure losses are neglected \\
\hline
\end{tabular}

1. TIT $=1350^{\circ} \mathrm{C}$, achievable with novel heat-resistant membranes and Ceramic Matrix Composites (CMC) materials for the first stages of the turboexpander [43, 44].

2. TIT $=1100^{\circ} \mathrm{C}$, which requires heat-resistant membranes, Ni-based superalloys, and Thermal Barrier Coating (TBC) for the turbine [45].

3. TIT $=900^{\circ} \mathrm{C}$, in case state-of-the-art $\mathrm{O}_{2}$ membranes are used; $\mathrm{TBC}$ may not be required and Ni-based superalloys should be used for the turbine.

4. TIT $=600^{\circ} \mathrm{C}$, in case Ni-based superalloys are not used for manufacturing the turbine blades, as it is in conventional steam expanders [46]. Water injection between the membrane reactor and the turbine is required for quenching, as shown in Fig. 1.

Cases 3 and 4 are feasible with the current level of technological development. $\mathrm{Ba}_{0.5} \mathrm{Sr}_{0.5} \mathrm{Co}_{0.8} \mathrm{Fe}_{0.2} \mathrm{O}_{3-\delta}$ (BSCF) is primarily considered as the state-of-the-art membrane material due to the high oxygen flux achieved in the range $850-900^{\circ} \mathrm{C}$. Nevertheless, the operating temperature of BSCF is limited by the large creep rate under high temperature operation $[47,48]$. For both case 1 and case 2, it is required to develop oxygen membranes capable of working at very high temperatures, such as $\mathrm{Ca}_{0.5} \mathrm{Sr}_{0.5} \mathrm{Fe}_{0.2} \mathrm{Mn}_{0.8} \mathrm{O}_{3-\delta}$ (CSFM) [49]. Moreover, case 1 requires the development of CMC materials for the expander, since blade cooling is not considered at this stage of the project (compressed air is not available, cooling should be performed with liquid water or with a closed-loop strategy). CMC materials are known to be negatively affected by the presence of steam, which is expected to be a large fraction of the expanding gas stream in this application. Therefore, a suitable Environmental Barrier Coating (EBC) should be also developed, as already proposed for some modern aeronautical gas turbine engines [50].

All components are treated as 0D units using Aspen Plus ${ }^{\circledR}$ as a simulation tool. The membranes are modelled as a separator that selectively separates the required stoichiometric oxygen from the main air flow. The permeated oxygen is assumed to be entirely consumed through reaction 3 , hence $\mathrm{NH}_{3}$ and $\mathrm{O}_{2}$ are not present at reactor outlet. The reactor development is likely to involve recirculation and forced convection, but this is not detailed here and will be the object of future assessments. The Peng-Robinson equation of state is adopted for the calculation of thermodynamic properties of the fluid mixtures.

\section{Results and discussion}

\subsection{Scheme A: constrained pressure ratio}

Table 3 shows the main results of the simulations that implement scheme A, for both atmospheric and sub-atmospheric configurations. Four TIT values are considered, which 
reflect different possible levels of technological development, as discussed in the previous section. For the sub-atmospheric configuration, the results refer to the condition where the expansion pressure is optimized to maximize the system efficiency.

Table 3. Main stream properties and system efficiency results, in the four considered cases of TIT, considering both atmospheric and optimized sub-atmospheric scheme A.

\begin{tabular}{lllllllll}
\hline Variable & units & \multicolumn{2}{c}{ case 1} & \multicolumn{2}{c}{ case 2 } & \multicolumn{2}{c}{ case 3 } & case 4 \\
\hline $\mathrm{T}_{\text {out }, M R}$ & {$\left[{ }^{\circ} \mathrm{C}\right]$} & 1350 & 1350 & 1100 & 1100 & 900 & 900 & 900 \\
$\mathrm{~T}_{\text {in,turb }}$ & {$\left[{ }^{\circ} \mathrm{C}\right]$} & 1350 & 1350 & 1100 & 1100 & 900 & 900 & 600 \\
$\mathrm{p}_{M R}$ & {$[\mathrm{bar}]$} & 50 & 18.1 & 50 & 20 & 50 & 20 & 50 \\
$\mathrm{p}_{\text {out }, \text { turb }}$ & {$[\mathrm{bar}]$} & 1.01 & 0.16 & 1.01 & 0.19 & 1.01 & 0.19 & 1.01 \\
$\mathrm{~T}_{\text {out }, \text { turb }}$ & {$\left[{ }^{\circ} \mathrm{C}\right]$} & 571 & 459 & 416 & 331 & 297 & 225 & 126 \\
$x_{\mathrm{H}_{2} \mathrm{O}, \text { in,turb }}$ & {$\left[\% \%_{\mathrm{vol}}\right]$} & 90.1 & 89.6 & 90.8 & 90.4 & 91.4 & 91.0 & 92.3 \\
$\mathrm{H}_{2} \mathrm{O}_{\text {produced }}$ & {$\left[\frac{\mathrm{mol}_{\mathrm{H}_{2} \mathrm{O}}}{\mathrm{mol}_{\mathrm{NH}_{3}}}\right]$} & 1.47 & 1.18 & 1.47 & 1.25 & 1.47 & 1.25 & 1.47 \\
$\eta_{\text {el }, \text { LHV }}$ & {$[\%]$} & 51.80 & 53.75 & 46.38 & 48.11 & 41.42 & 42.96 & 32.75 \\
\hline
\end{tabular}

It is evident that the TIT significantly affects the system performance, due to a larger Carnot efficiency achieved with a higher maximum cycle temperature. Therefore, the development of oxygen membranes capable of working at very high temperature is crucial to reach high efficiency. System electric efficiency values are below modern combined cycles, but mostly above open-cycle gas turbine plants (despite the adoption of an uncooled expansion, as assumed here, would increase also the performance of gas turbine plants). In case 1 , the system efficiency is comparable to that of modern combined cycles equipped with post-combustion $\mathrm{CO}_{2}$ capture. Nevertheless, the HiPowAR system is simpler. The expanded fluid is a mixture of water vapour and nitrogen, with steam molar fraction above $90 \%$, as indicated in Table 3. Despite the envisaged TIT range is similar to that of gas turbine cycles, the working fluid is almost pure water as in conventional steam cycles. This is expected as the stoichiometric reaction (3) would produce a mixture of $75 \% \%_{\text {vol }} \mathrm{H}_{2} \mathrm{O}$ and $25 \%{ }_{\mathrm{vol}} \mathrm{N}_{2}$, and using additional water as a moderating agent increases the water percentage at the MR outlet. Therefore, case 4 is included to assess the potential of using a commercially available steam expander, which could face a temperature up to $600^{\circ} \mathrm{C}$. Note that in case 4 water is injected before the turbine inlet to reduce the temperature seen by the expander (dotted blue stream in Fig. 1).

In the four cases implementing atmospheric expansion, 1.47 moles of liquid water are produced (stream 11 in Fig. 1) per mole of ammonia entering the system. Assuming a scenario where ammonia is produced using hydrogen from water electrolysis, the system allows the recovery of $97.8 \%$ of the water embedded in the ammonia fuel, which could be an important advantage over conventional hydrogen-fired gas turbines cycles in the future, where water is substantially diluted by excess air and is not easily recoverable from flue gas condensation. Moreover, streams 9 and 16 (Fig. 1) contain $93.8 \% \%_{\mathrm{vol}}$ and $97.4 \%$ vol nitrogen, respectively, which potentially allows for cheap $\mathrm{N}_{2}$ production. This could be interesting in a scenario where $\mathrm{NH}_{3}$ is one of the main energy vectors, since $\mathrm{N}_{2}$ production for ammonia synthesis is an energy-intensive process. The possibility to easily separate $\mathrm{H}_{2} \mathrm{O}$ and $\mathrm{N}_{2}$ is due to the use of a $\mathrm{O}_{2}$ membrane. Therefore, it is not possible to achieve the same result in conventional systems such as gas turbines and steam cycles when fed with $\mathrm{NH}_{3}$.

In Table 3, the temperature at the expander outlet is also shown. In case 4, the expanded fluid is close to its dew point since, at atmospheric pressure, condensation starts at about $100^{\circ} \mathrm{C}$. Therefore, the larger expansion ratios envisaged for the sub-atmospheric scheme A and for the scheme B are not considered for case 4 . In cases 1, 2, and 3, the temperature at turbine outlet is relatively large for the atmospheric expansion configuration, hence a larger expansion ratio could significantly increase the system efficiency. In cases 1 and 2, the 
moderating water is heated up to the saturation temperature, and partial water evaporation occurs due to the large temperature of the turbine discharge stream for both atmospheric and sub-atmospheric configurations. Note that both the ammonia evaporator and the water preheater are modelled by imposing a pinch-point temperature of $10^{\circ} \mathrm{C}$. In the water preheater the pinch point is located where the hot fluid starts condensing. Partial condensation of the hot fluid is allowed to preheat the liquid water, whose initial temperature is $40^{\circ} \mathrm{C}$.

The sub-atmospheric implementation of scheme A is conceived to achieve high efficiency with a pressure lower than 50 bar within the MR, for which the membranes' mechanical resistance and sealing technology is yet to be proven. Figure 4 shows the results of the simulations, in which a sub-atmospheric expansion pressure is coupled with a reduced pressure within the MR to allow an efficient $\mathrm{NH}_{3}$ evaporation. When the expansion pressure is about 1 bar, the pressure within the MR should be 50 bar, hence both the plant scheme and the efficiency are identical to those in Fig. 1. For each sub-atmospheric pressure, the maximum system pressure is computed within Aspen Plus ${ }^{\circledR}$ to allow the $10^{\circ} \mathrm{C}$ pinch point difference between $\mathrm{H}_{2} \mathrm{O}$ condensation and $\mathrm{NH}_{3}$ evaporation, the resulting monotonic profile is shown by the black dotted line in Fig. 4.

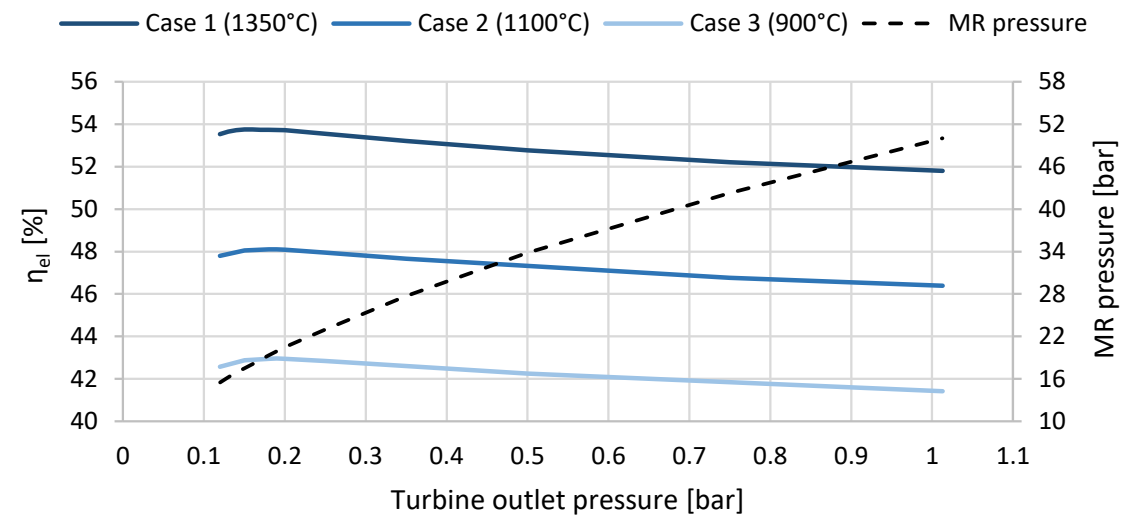

Fig. 4. Electric efficiency and MR pressure as a function of the turbine outlet pressure, for the three considered cases of TIT, adopting scheme A.

The main simulation results at the optimal expansion pressure are indicated in Table 3, while the atmospheric expansion configuration corresponds to the lowest efficiency point shown in Fig. 4, for cases 1, 2, and 3. Around the optimal point the efficiency keeps fairly constant, hence the optimal expansion pressure range is about 0.15-0.2 bar, corresponding to a MR pressure in the range 17-20 bar, which is a pressure level already tested for $\mathrm{O}_{2}$ membranes [42]. Note that despite the pressure within the MR decreases at lower expansion pressure, the expansion ratio across the turbine actually increases (from 50 to more than 100). Therefore, the system efficiency increases and the turbine outlet temperature significantly decreases when considering the optimized sub-atmospheric configuration compared to the atmospheric scheme (see Table 3). Nevertheless, the outlet turbine temperature in the optimal expansion pressure condition is still a large value in general, hence larger expansion ratios could benefit the system performance, as investigated in scheme B.

A drawback of sub-atmospheric expansion is related to water production. The lower condenser pressure increases the $\mathrm{H}_{2} \mathrm{O}$ mass flow rate in stream 10, reducing that of stream 
15 (Fig. 2). This effect can be seen in Table 3, which shows that a reduced amount of water is produced adopting a sub-atmospheric configuration. For instance, in case 1 only $78.6 \%$ of the water embedded in the green $\mathrm{NH}_{3}$ is recovered in the optimized sub-atmospheric configuration. Nevertheless, after the off-gas is cooled through heat recovery, a further step of condensation down to $40^{\circ} \mathrm{C}$ and liquid separation would allow the recovery of $97.8 \%$ of water embedded in the input $\mathrm{NH}_{3}$, due to condensation at atmospheric pressure.

To summarize, the sub-atmospheric implementation of scheme A brings about a significant advantage in terms of efficiency, especially when the TIT is large. Moreover, the lower reactor pressure offers several advantages in terms of manufacturing and operational complexity as well as costs, as already discussed. For completeness, Table 4 shows the detailed simulation results for the optimized sub-atmospheric scheme A with $\mathrm{TIT}=1350^{\circ} \mathrm{C}$ (Fig. 2).

Table 4. Thermodynamic conditions and flow rates in all scheme points, considering the subatmospheric scheme A (Fig. 2) with $\mathrm{TIT}=1350^{\circ} \mathrm{C}$ and optimized expansion pressure (case 1).

\begin{tabular}{rrrrrrrrrrrr}
\hline Stream & $\mathrm{T}\left[{ }^{\circ} \mathrm{C}\right]$ & $\mathrm{p}[\mathrm{bar}]$ & $\dot{m}[\mathrm{~kg} / \mathrm{s}]$ & $\dot{n}[\mathrm{kmol} / \mathrm{s}]$ & $\mathrm{NH}_{3}$ & $\mathrm{H}_{2}$ & $\mathrm{H}_{2} \mathrm{O}$ & $\mathrm{N}_{2}$ & $\mathrm{O}_{2}$ & $\mathrm{NH}_{3}(\mathrm{~L})$ & $\mathrm{H}_{2} \mathrm{O}(\mathrm{L})$ \\
\hline 1 & 25.0 & 9.9 & 10.0 & 0.587 & 0.0 & 0.0 & 0.0 & 0.0 & 0.0 & 100.0 & 0.0 \\
2 & 25.3 & 18.1 & 10.0 & 0.587 & 0.0 & 0.0 & 0.0 & 0.0 & 0.0 & 100.0 & 0.0 \\
3 & 45.8 & 18.1 & 10.0 & 0.587 & 100.0 & 0.0 & 0.0 & 0.0 & 0.0 & 0.0 & 0.0 \\
4 & 166.0 & 18.1 & 10.0 & 0.587 & 100.0 & 0.0 & 0.0 & 0.0 & 0.0 & 0.0 & 0.0 \\
5 & 1350.0 & 18.1 & 53.564 & 2.810 & 0.0 & 0.0 & 89.55 & 10.45 & 0.0 & 0.0 & 0.0 \\
6 & 459.4 & 0.16 & 53.564 & 2.810 & 0.0 & 0.0 & 89.55 & 10.45 & 0.0 & 0.0 & 0.0 \\
7 & 55.8 & 0.16 & 53.564 & 2.810 & 0.0 & 0.0 & 88.95 & 10.45 & 0.0 & 0.0 & 0.60 \\
8 & 55.5 & 0.16 & 53.564 & 2.810 & 0.0 & 0.0 & 79.17 & 10.45 & 0.0 & 0.0 & 10.38 \\
9 & 40.0 & 0.16 & 53.564 & 2.810 & 0.0 & 0.0 & 6.71 & 10.45 & 0.0 & 0.0 & 82.84 \\
10 & 40.0 & 0.16 & 11.621 & 0.482 & 0.0 & 0.0 & 39.11 & 60.89 & 0.0 & 0.0 & 0.0 \\
11 & 272.8 & 1.01 & 11.621 & 0.482 & 0.0 & 0.0 & 39.11 & 60.89 & 0.0 & 0.0 & 0.0 \\
12 & 77.9 & 1.01 & 11.621 & 0.482 & 0.0 & 0.0 & 39.11 & 60.89 & 0.0 & 0.0 & 0.0 \\
13 & 40.0 & 0.16 & 41.943 & 2.328 & 0.0 & 0.0 & 0.0 & 0.0 & 0.0 & 0.0 & 100.0 \\
14 & 40.0 & 1.01 & 41.943 & 2.328 & 0.0 & 0.0 & 0.0 & 0.0 & 0.0 & 0.0 & 100.0 \\
15 & 40.0 & 1.01 & 12.470 & 0.692 & 0.0 & 0.0 & 0.0 & 0.0 & 0.0 & 0.0 & 100.0 \\
16 & 40.0 & 1.01 & 29.473 & 1.636 & 0.0 & 0.0 & 0.0 & 0.0 & 0.0 & 0.0 & 100.0 \\
17 & 40.2 & 18.1 & 29.473 & 1.636 & 0.0 & 0.0 & 0.0 & 0.0 & 0.0 & 0.0 & 100.0 \\
18 & 207.5 & 18.1 & 29.473 & 1.636 & 0.0 & 0.0 & 29.43 & 0.0 & 0.0 & 0.0 & 70.57 \\
19 & 25.0 & 1.01 & 67.222 & 2.330 & 0.0 & 0.0 & 0.0 & 79.0 & 21.0 & 0.0 & 0.0 \\
20 & 100.0 & 1.01 & 53.130 & 1.890 & 0.0 & 0.0 & 0.0 & 97.41 & 2.59 & 0.0 & 0.0 \\
\hline
\end{tabular}

\subsection{Scheme B: independent pressure levels}

Table 5 summarizes the results for cases 1, 2, and 3 for MR pressure equal to 50 bar and 100 bar, adopting the system configuration of Fig. 3. In each subcase, the minimum system pressure is optimized to maximize the system efficiency.

Table 5. Simulation results for scheme B, at different values of TIT and MR pressure

\begin{tabular}{llllllll}
\hline Variable & units & \multicolumn{2}{c}{ case 1} & \multicolumn{2}{c}{ case 2} & \multicolumn{2}{c}{ case 3 } \\
\hline $\mathrm{T}_{\text {out }, M R}=\mathrm{T}_{\text {in,turb }}$ & {$\left[{ }^{\circ} \mathrm{C}\right]$} & 1350 & 1350 & 1100 & 1100 & 900 & 900 \\
$\mathrm{p}_{M R}$ & {$[\mathrm{bar}]$} & 100 & 50 & 100 & 50 & 100 & 50 \\
$\mathrm{p}_{\text {out }, \text { turb } \text { opt }}$ & {$[\mathrm{bar}]$} & 0.12 & 0.11 & 0.15 & 0.14 & 0.12 & 0.14 \\
$\mathrm{~T}_{\text {out }, \text { turb }}$ & {$\left[{ }^{\circ} \mathrm{C}\right]$} & 251 & 306 & 165 & 214 & 62 & 126 \\
$\eta_{\text {el }, \text { LHV }}$ & {$[\%]$} & 54.81 & 52.74 & 49.27 & 48.0 & 43.96 & 42.78 \\
\hline
\end{tabular}


With this scheme, complete ammonia evaporation is not always possible, and a system for ammonia evaporation inside the reactor should be designed in some cases. It is possible to draw the following conclusions:

- Ammonia evaporation is easier when the TIT is large and the expansion ratio is low, due to a larger temperature of the turbine discharge stream. Therefore, complete evaporation is always possible when $\mathrm{TIT}=1350^{\circ} \mathrm{C}$. If $\mathrm{TIT}=1100^{\circ} \mathrm{C}, \mathrm{NH}_{3}$ can be completely vaporized if the MR pressure is $50 \mathrm{bar}$, and partially vaporized in case the pressure is 100 bar. When TIT $=900^{\circ} \mathrm{C}, \mathrm{NH}_{3}$ is partially vaporized if the MR pressure is 50 bar, whereas in the 100 bar case the turbine discharge flow is directly sent to the condenser due to the very low residual temperature.

- If the reactor pressure is limited at 50 bar due to sealing technology and membrane mechanical resistance, scheme B performs better than the atmospheric scheme A. However, a fairer comparison would look at sub-atmospheric optimized scheme A and scheme B, leading to nearly the same efficiency values for case 2 and case 3 , and an efficiency advantage for scheme A in case 1 . Nevertheless, if the residual sensible heat of stream 6 (Fig. 3) is used to preheat the moderating water, the efficiency of the optimized sub-atmospheric scheme A would be approximately equal to that of scheme $\mathrm{B}$ with an MR pressure of 50 bar for all TIT values. The reactor pressure in the subatmospheric scheme A would only be 20 bar, providing investment and safety benefits.

- On the other hand, if the MR could be designed to withstand a pressure of $100 \mathrm{bar}$, scheme $\mathrm{B}$ offers a larger efficiency. If the heat available in the $\mathrm{O}_{2}$-depleted air is used to preheat the moderating water, then it would be even possible to overcome $55 \%$ efficiency with scheme B.

Finally, it should also be considered that scheme A would have an expansion ratio of about 100 , while scheme $\mathrm{B}$ would require a ratio up to 800 , which is a challenge for the expander design.

\section{Conclusions}

This work have presented and discussed a series of simulations, with the aim of assessing the potential efficiency of the HiPowAR power generation system. This adopts ammonia as input fuel, which is oxidized by pure oxygen in a membrane reactor, using water as a moderating agent. The outlet stream from the reactor is a $\mathrm{H}_{2} \mathrm{O}-\mathrm{N}_{2}$ mixture with a large steam fraction (about $90 \%$ vol , which is expanded from high temperature and pressure to atmospheric or even sub-atmospheric pressure (adopting a compressor for off-gas repressurization) to generate mechanical work.

Two potential schemes have been investigated: scheme A features a constrained expansion ratio across the turbine to exploit the heat integration between water condensation and ammonia evaporation, whereas scheme B maximizes the expansion ratio across the turbine by adopting a large pressure within the reactor. Both schemes have an optimal sub-atmospheric condensation pressure, since at low pressure both the turbine output and the compressor consumption increase. It is found that the TIT is of major importance for the system efficiency, hence $\mathrm{O}_{2}$ membranes capable of working at very high temperature should be developed for this application. If the maximum reactor pressure is limited to 50 bar (e.g., due to mechanical resistance and sealings issues), the two schemes achieve very similar efficiency values $\left(53-54 \%\right.$ at $\left.\mathrm{TIT}=1350^{\circ} \mathrm{C}\right)$. If a MR pressure of 100 bar is allowed, the independent-pressure-levels configuration (scheme B) slightly outperforms the constrained-pressure-ratio one (scheme A), approaching $55 \%$ at $1350^{\circ} \mathrm{C}$, which is a promising target for the future evolution of the HiPowAR plant concept. 
Regardless of the TIT value, the optimized scheme A features a lower reactor pressure of 20 bar, providing investment and safety benefits. Moreover, the expansion ratio in scheme B could be as high as 800 , while scheme A works with an expansion ratio of about 100 . In all cases the system could release, as a net output, $97.8 \%$ of the water embedded in the input green ammonia, making easier its recovery, which is an advantage compared to conventional technologies for electricity generation.

The HiPowAR project has received funding from the European Union's Horizon 2020 research and innovation programme under grant agreement n. 951880 .

\section{References}

1. C.S. Mørch, A. Bjerre, M.P. Gøttrup, S.C. Sorenson, J. Schramm, Fuel, 90, 854-864 (2011)

2. M. Kishimoto, H. Muroyama, S. Suzuki, M. Saito, T. Koide, Y. Takahashi, T. Horiuchi, H. Yamasaki, S. Matsumoto, H. Kubo, N. Takahashi, A. Okabe, S. Ueguchi, M. Jun, A. Tateno, T. Matsuo, T. Matsui, H. Iwai, H. Yoshida, K. Eguchi, Fuel Cells, 20, 80-88 (2020)

3. O. Kurata, N. Iki, T. Matsunuma, T. Inoue, T. Tsujimura, H. Furutani, H. Kobayashi, A. Hayakawa, Proc. Combust. Inst., 36, 3351-3359 (2016)

4. European Commission, HiPowAR: Powering the way for renewable ammonia. https://ec.europa.eu/programmes/horizon2020/en/news/hipowar-powering-wayrenewable-ammonia (accessed June 29, 2021)

5. U. Pippardt, J. Böer, C. Bollert, A. Hoffmann, M. Heidenreich, R. Kriegel, M. Schulz, A. Simon, J. Ceram. Sci. Technol., 5, 309-316 (2014)

6. D.M. Turi, P. Chiesa, E. Macchi, A.F. Ghoniem, Energy, 96, 127-141 (2016)

7. Gencell A5 - Off-grid power solution. https://www.gencellenergy.com/ourproducts/gencell-a5/ (accessed June 25, 2021)

8. Cross-ministerial Strategic Innovation Promotion Program (SIP), Energy Carriers. https://www.jst.go.jp/sip/pdf/SIP_energycarriers2015_en.pdf (accessed June 25, 2021)

9. Campfire Project. https://wir-campfire.de/en/home-english/ (accessed June 25, 2021)

10. P.G. Grimes, SAE Trans., 74, 281-299, 316-326 (1966)

11. W. Cornelius, L.W. Huellmantel, H.R. Mitchell, SAE Trans., 74, 300-326 (1966)

12. J.T. Gray, E. Dimitroff, N.T. Meckel, R.D. Quillian, SAE Trans., 75, 785-807 (1967)

13. E.S. Starkman, G.S. Samuelsen, Symp. Combust., 11, 1037-1045 (1967)

14. T.J. Pearsall, C.G. Garabedian, SAE Trans., 76, 3213-3221 (1968)

15. C. Lhuillier, P. Brequigny, F. Contino, C. Mounaïm-Rousselle, Fuel, 269, 117448 (2020)

16. C. Lhuillier, P. Brequigny, F. Contino, C. Mounaïm-rousselle, $14^{\text {th }}$ Int. Conf. Engines Veh. (2019)

17. M. Comotti, S. Frigo, Int. J. Hydrogen Energy, 40, 10673-10686 (2015)

18. S. Frigo, R. Gentili, N. Doveri, SAE Tech. Pap., 2012-32-0019 (2012)

19. P. Dimitriou, R. Javaid, Int. J. Hydrogen Energy, 45, 7098-7118 (2020)

20. A.A. Khateeb, T.F. Guiberti, X. Zhu, M. Younes, A. Jamal, W.L. Roberts, Int. J. Hydrogen Energy, 45, 22008-22018 (2020) 
21. O. Kurata, T. Matsunuma, T. Inoue, Proc. ASME 2017 Power Conf. Jt. With ICOPE17 (2017)

22. E.C. Okafor, K.D.K.A. Somarathne, A. Hayakawa, T. Kudo, O. Kurata, N. Iki, H. Kobayashi, Proc. Combust. Inst., 37, 4597-4606 (2019)

23. N.A. Hussein, A. Valera-Medina, A.S. Alsaegh, Energy Procedia, 158, 2305-2310 (2019)

24. M. Guteša Božo, M.O. Vigueras-Zuniga, M. Buffi, T. Seljak, A. Valera-Medina, Appl. Energy, 251, 113334 (2019)

25. A. Hayakawa, T. Goto, R. Mimoto, T. Kudo, H. Kobayashi, Mech. Eng. J., 2, 14 00402 (2015)

26. H. Nozari, A. Karabeyoglu, Fuel, 159, 223-233 (2015)

27. H. Xiao, A. Valera-Medina, P.J. Bowen, Energy and Fuels, 31, 8631-8642 (2017)

28. A. Valera-Medina, M. Gutesa, H. Xiao, D. Pugh, A. Giles, B. Goktepe, R. Marsh, P. Bowen, Int. J. Hydrogen Energy, 44, 8615-8626 (2019)

29. B. Mei, X. Zhang, S. Ma, M. Cui, H. Guo, Z. Cao, Y. Li, Combust. Flame, 210, 236246 (2019)

30. Alkammonia project description. https://cordis.europa.eu/project/id/325343 (accessed June 26, 2021)

31. Gencell, Presentation of the A5 unit, in: Ammon. Energy Conf., 2020. https://www.ammoniaenergy.org/paper/gencells-ammonia-fuelled-off-grid-powergeneration-solution/

32. B. Cox, K. Treyer, J. Power Sources, 275, 322-335 (2015)

33. B. Stoeckl, M. Preininger, V. Subotić, C. Gaber, M. Seidl, P. Sommersacher, H. Schroettner, C. Hochenauer, J. Electrochem. Soc., 166, F774-F783 (2019)

34. J. Yang, A.F.S. Molouk, T. Okanishi, H. Muroyama, T. Matsui, K. Eguchi, ACS Appl. Mater. Interfaces., 7, 28701-28707 (2015)

35. T. Okanishi, K. Okura, A. Srifa, H. Muroyama, T. Matsui, M. Kishimoto, M. Saito, H. Iwai, H. Yoshida, M. Saito, T. Koide, H. Iwai, S. Suzuki, Y. Takahashi, T. Horiuchi, H. Yamasaki, S. Matsumoto, S. Yumoto, H. Kubo, J. Kawahara, A. Okabe, Y. Kikkawa, T. Isomura, K. Eguchi, Fuel Cells, 17, 383-390 (2017)

36. W.Y. Tan, Energy Sources, Part A Recover. Util. Environ. Eff., 36, 2410-2419 (2014)

37. O. Grasham, V. Dupont, M.A. Camargo-Valero, P. García-Gutiérrez, T. Cockerill, Appl. Energy, 240, 698-708 (2019)

38. Y. Wang, Y. Gu, H. Zhang, J. Yang, J. Wang, W. Guan, J. Chen, B. Chi, L. Jia, H. Muroyama, T. Matsui, K. Eguchi, Z. Zhong, Appl. Energy, 270, 115185 (2020)

39. Y. Wang, J. Yang, J. Wang, W. Guan, B. Chi, L. Jia, J. Chen, H. Muroyama, T. Matsui, K. Eguchi, J. Electrochem. Soc., 167, 064501 (2020)

40. G. Cinti, G. Discepoli, E. Sisani, U. Desideri, Int. J. Hydrogen Energy, 41, 1358313590 (2016)

41. R. Kriegel, R. Kircheisen, M. Lampinen, V. Ristimaeki, US 2017/0030304 A1 (2017)

42. L.L. Anderson, P.A. Armstrong, R.R. Broekhuis, M.F. Carolan, J. Chen, M.D. Hutcheon, C.A. Lewinsohn, C.F. Miller, J.M. Repasky, D.M. Taylor, C.M. Woods, Solid State Ionics, 288, 331-337 (2016)

43. R.J. Boyle, A.H. Parikh, M.C. Halbig, V.K. Nagpal, in: Proc. ASME Turbo Expo 2013 Turbine Tech. Conf. Expo, GT2013-95104 (2013) 
44. N.P. Padture, Nat. Mater, 15, 804-809 (2016)

45. J.D. Osorio, A. Toro, J.P. Hernández-Ortiz, Dyna, 79, 149-158 (2012)

46. S. Osgerby, Structural Alloys for Power Plants: Operational Challenges and HighTemperature Materials (Woodhead Publishing Series, 2014)

47. J.X. Yi, H.L. Lein, T. Grande, S. Yakovlev, H.J.M. Bouwmeester, Solid State Ionics, 180, 1564-1568 (2009)

48. B. Rutkowski, J. Malzbender, T. Beck, R.W. Steinbrech, L. Singheiser, J. Eur. Ceram. Soc., 31, 493-499 (2011)

49. R. Kriegel, B. Jager, R. Kircheisen, Production of $\mathrm{N}_{2}$-free syngas by methane combustion with consecutive reforming, Key Note Lecture, $14^{\text {th }}$ ICCMR (2019)

50. D. Tejero-Martin, C. Bennett, T. Hussain, J. Eur. Ceram. Soc., 41, 1747-1768 (2021) 